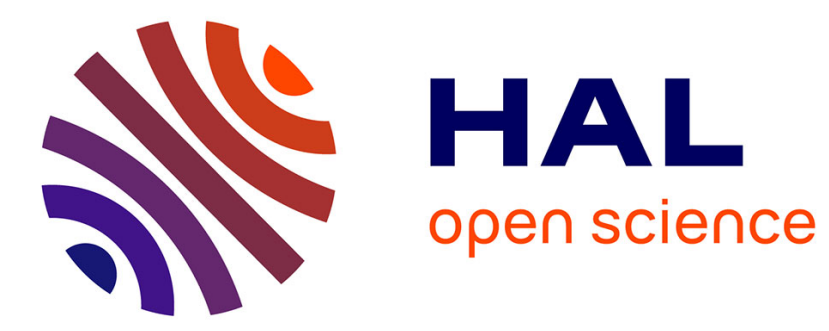

\title{
Influence of gaussian light statistics on resonant multiphoton ionization
}

F. Sanchez

\section{To cite this version:}

F. Sanchez. Influence of gaussian light statistics on resonant multiphoton ionization. Journal de Physique Lettres, 1978, 39 (3), pp.35-36. 10.1051/jphyslet:0197800390303500 . jpa-00231436

\section{HAL Id: jpa-00231436 https://hal.science/jpa-00231436}

Submitted on 1 Jan 1978

HAL is a multi-disciplinary open access archive for the deposit and dissemination of scientific research documents, whether they are published or not. The documents may come from teaching and research institutions in France or abroad, or from public or private research centers.
L'archive ouverte pluridisciplinaire HAL, est destinée au dépôt et à la diffusion de documents scientifiques de niveau recherche, publiés ou non, émanant des établissements d'enseignement et de recherche français ou étrangers, des laboratoires publics ou privés. 


\title{
LE JOURNAL DE PHYSIQUE-LETTRES
}

\author{
Classification \\ Physics Abstracts
}

$32.80 \mathrm{~K}-62.65 \mathrm{~B}$

\section{INFLUENCE OF GAUSSIAN LIGHT STATISTICS ON RESONANT MULTIPHOTON IONIZATION}

\author{
F. SANCHEZ \\ Centre d'Etudes Nucléaires de Saclay, Service de Physique Atomique, \\ BP No 2, 91190 Gif sur Yvette, France
}

(Reçu le 3 juin 1977, révisé le 24 novembre 1977, accepté le 8 décembre 1977)

\begin{abstract}
Résumé. - L'influence de la cohérence du rayonnement dans les processus d'ionisation résonnante est étudiée dans le cas particulier d'une statistique gaussienne. Il est montré comment cette influence dépend des forces respectives des deux transitions.

Abstract. - The influence of radiation coherence effects on the resonant ionization multiphoton process in a multimode laser is studied for the case when Gaussian statistics are applicable. It is shown how this influence depends on the relative field couplings of the two transitions.
\end{abstract}

Recent experiments [1] on one-step $n$-photon ionization allowed us to give a detailed picture of Q-switched laser radiation statistics [2]. In particular, we found that when the number of independent spectral domains is large with respect to $n$, this radiation can be described by Gaussian statistics, explaining the observed enhancement coherence factor $n$ ! of the $n$-photon probability, with respect to the bandwidthlimited pulse of the same average intensity.

Such an enhancement of $n$ ! was predicted a long time ago [3], but it only referred to stationary thermal light with respect to a Glauber coherent state [4].

In the present paper, we predict the influence of the multimode laser Gaussian statistics on the two-step $n$-photon ionization, i.e. a $p$-photon excitation accompanied by an (n-p)-photon ionization. Such an effect is characterized by a resonance ionization profile [5].

Of course, the direct $n$-photon process is always present and competes coherently with the two-step process, resulting in an asymmetric Fano profile [6]. However we shall consider only the most interesting case for which the resonance is sharp, and we restrict the study to the spectral domain in which the direct process may be neglected.

Two simultaneous papers $[7,8]$ have dealt with this problem, but only for particular situations. One [7] explains in detail the case $n=2$, while the other deals with the case $n-p=1, n>2$. These two cases are essentially different as we shall show below.

Following the semi-classical description of the two-step ionization process of Crance and Feneuille [9], we denote by $J$ the coupling between the fundamental state and the resonant state of the continuum, by $K$ and $L$ the respective couplings corresponding to the first and second step, and by $S$ the detuning. These quantities are related to the field intensity $I$ and the field frequency $\omega$ by :

$$
\begin{aligned}
J & =j I^{(n / 2)} \\
K & =k I^{(p / 2)} \\
L & =l I^{(n-p / 2)} \\
S & =p\left(\omega-\omega_{0}\right)
\end{aligned}
$$

where $j, k, l$ and $\omega_{0}$ are atomic parameters. We only consider the quasi-stationary solutions of these authors [9], i.e. the pulse duration is sufficient to make transient effects neglegible, and we restrict our attention to the central domain $|S| \ll K L / J$. Then. the ionization rate for a bandwidth-limited pulse can be written as :

$$
\left(\frac{\mathrm{d} P}{\mathrm{~d} t}\right)_{0}=\frac{K^{2} L^{2}}{K^{2}+S^{2}} \quad\left(K \gg L^{2} \gg J^{2}\right)
$$

or

$$
\left(\frac{\mathrm{d} P}{\mathrm{~d} t}\right)_{0}=\frac{K^{2} L^{2}}{L^{4}+\left(S+\alpha L^{2}\right)^{2}} \quad\left(L^{2} \gg K \gg L J\right)
$$

where $\alpha$ is an additive atomic parameter representing the ratio between field-induced shift and broadening of resonance. In the previous equations, non-resonant light shifts have been ignored.

The first solution corresponds to the case where the first step (p-photon excitation) is the dominant 
process, (as is generaly the case for $n=2$ ), while the second solution corresponds to the case where the second step ( $n-p$ photon ionization) dominates.

For a multimode pulse, the fluctuations of instantaneous light intensity and instantaneous frequency must be taken into account. However we shall consider the most interesting case for which the (field-induced) resonance spectral width is much greater than the radiation bandwidth. Then we may take the light as being monochromatic and only consider the intensity fluctuations. In other words, the coherence time of the field is much greater than the characteristic time of the resonant process. This means that the solutions (2) may be averaged over intensity, with the help of relations (1). When Gaussian statistics are applicable [10] one has :

$$
\left\langle\frac{\mathrm{d} P}{\mathrm{~d} t}\right\rangle=\frac{1}{\langle I\rangle} \int_{0}^{\infty}\left(\frac{\mathrm{d} P}{\mathrm{~d} t}\right)_{0} \mathrm{e}^{-I /\langle I\rangle} \mathrm{d} I .
$$

One obtains the enhancements :

$$
\left\langle\frac{\mathrm{d} P}{\mathrm{~d} t}\right\rangle /\left(\frac{\mathrm{d} P}{\mathrm{~d} t}\right)_{0}=\left(1+S_{1}^{2}\right) \int_{0}^{\infty} \frac{u^{n} \mathrm{e}^{-u} \mathrm{~d} u}{u^{p}+S_{1}^{2}}
$$

or

$$
\begin{aligned}
& \left\langle\frac{\mathrm{d} P}{\mathrm{~d} t}\right\rangle /\left(\frac{\mathrm{d} P}{\mathrm{~d} t}\right)_{0}= \\
& \quad=\left[1+\left(S_{1}+\alpha\right)^{2}\right] \int_{0}^{\infty} \frac{u^{n} \mathrm{e}^{-u} \mathrm{~d} u}{u^{2 n-2 p}+\left(S_{1}+\alpha u^{n-p}\right)^{2}}
\end{aligned}
$$

where $S_{1}$ is twice the ratio between $S$ and the monomode resonance bandwidth. If one consider the enhancement of the resonance curve area

$$
h_{\mathrm{a}}=\frac{\int\left\langle\frac{\mathrm{d} P}{\mathrm{~d} t}\right\rangle \mathrm{d} S}{\int\left(\frac{\mathrm{d} P}{\mathrm{~d} t}\right)_{0} \mathrm{~d} S}
$$

one obtains :

$$
h_{\mathrm{a}}=\left(n-\frac{p}{2}\right) ! \quad\left(K \gg L^{2} \gg J^{2}\right)
$$

or

$$
h_{\mathrm{a}}=p ! \quad\left(L^{2} \gg K \gg L J\right) .
$$

If one consider now the enhancement of the maximal value $h_{\mathrm{m}}$, one easily obtains :

or

$$
\begin{aligned}
& h_{\mathrm{m}}=(n-p) ! \\
& h_{\mathrm{m}}=(2 p-n) ! F(|\alpha|)
\end{aligned}
$$

where $F$ is a monotonically decreasing function of $|\alpha|$, with $F(0)=1$.

For the sake of comparison between the two kinds of two-step processes, let us designate by $q$ the number of photons in the stronger step, that is $q=p$ for the first case and $q=n-p$ for the second. One obtains from (5) and (6) :

$$
\begin{array}{ll}
\quad h_{\mathrm{a}}=\left(n-\frac{q}{2}\right) ! & h_{\mathrm{m}}=(n-q) ! \\
\text { or } h_{\mathrm{a}}=(n-q) ! & h_{\mathrm{m}}=(n-2 q) ! F(|\alpha|) .
\end{array}
$$

It is seen that for given values of $n$ and $q$, the first case (first step dominant) corresponds to a higher maximal enhancement $h_{\mathrm{m}}$ than the second case. As the reverse is true for the width enhancement $h_{\mathrm{a}} / h_{\mathrm{m}}$ the increase in the resonance width due to Gaussian statistics is smaller for the first case. This is illustrated on the figure for the case $n=4, q=1, \alpha=0$.

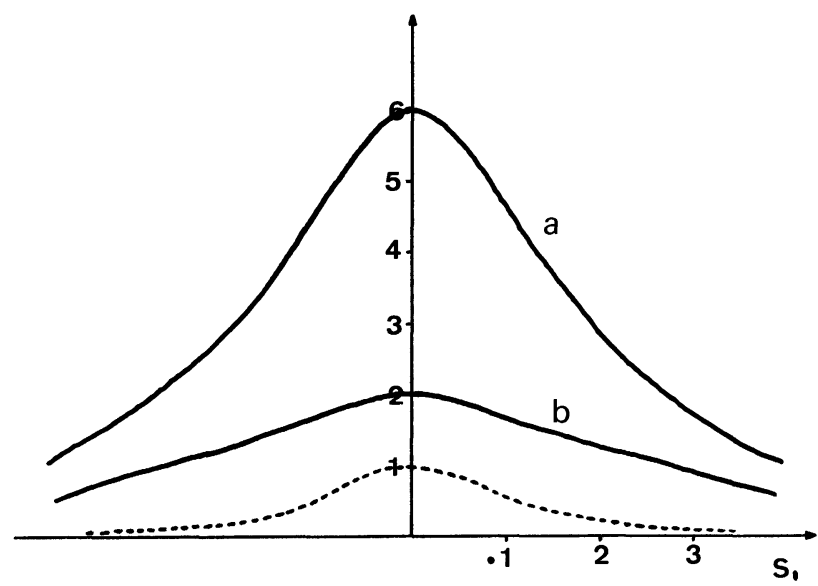

Fig. 1. - Shape of the resonance line, for $n=4, q=1, \alpha=0$ - - Bandwith-limited pulse. —_ Gaussian amplitude modulated pulse. $a$ ) First transition dominant ; $b$ ) second transition dominant.

\section{References}

[1] Lecompte, C., Mainfray, G., Manus, C. and Sanchez, F., Phys. Rev. Lett. 32 (1974) 265 and Phys. Rev. A 11 (1975) 1009. See also Krasinski, J., ChudzYnSKi, S., MajeWSKI, W. and Glodtz, M., Opt. Commun. 12 (1974) 304.

[2] Sanchez, F., Nuovo Cimento 11 (1975) 305.

[3] Lambropoulos, P., Kikuchi, C. and Osborn, R. K., Phys. Rev. 144 (1966) 1981. Agarwal, G. S., Phys. Rev. A 1 (1970) 1445 .

[4] Glauber, R. J., Phys. Rev. 131 (1963) 2766.

[5] Morellec, J., Normand, D. and Petite, G., Phys. Rev. A 14 (1976) 300 .
[6] Armstrong, L. Jr., Beers, B. L. and Feneuille, S., Phys. Rev. A 12 (1975) 1903.

[7] Armstrong, L. Jr., Lambropoulos, P. and Rahman, N. K., Phys. Rev. Lett. 36 (1976) 952.

[8] Mostowski, I., Phys. Lett. A 56 (1976) 87.

[9] Crance, M. and Feneuille, S., J. Physique Lett. 37 (1976) L-333 and Phys. Rev. A 16 (1977) 1587.

[10] The case of a small number of modes has been investigated by KovarskiI, V. A., Perel'man, N. F. and TodiRASHKU, S. S., Kvantovaya Elektron. (Moscow) 3 (1976) 1805, Sov. J. Quantum Electron. 6 (1976) 980. 